This item was submitted to Loughborough's Research Repository by the author.

Items in Figshare are protected by copyright, with all rights reserved, unless otherwise indicated.

\title{
Investigation of the effect of relative humidity on polymers by depth sensing
} indentation

PLEASE CITE THE PUBLISHED VERSION

http://dx.doi.org/10.1007/s10853-011-5729-8

PUBLISHER

(c) Springer

VERSION

AM (Accepted Manuscript)

LICENCE

CC BY-NC-ND 4.0

\section{REPOSITORY RECORD}

Altaf, Kazim, lan A. Ashcroft, and Richard J.M. Hague. 2019. "Investigation of the Effect of Relative Humidity on Polymers by Depth Sensing Indentation”. figshare. https://hdl.handle.net/2134/8689. 
This item was submitted to Loughborough's Institutional Repository (https://dspace.lboro.ac.uk/) by the author and is made available under the following Creative Commons Licence conditions.

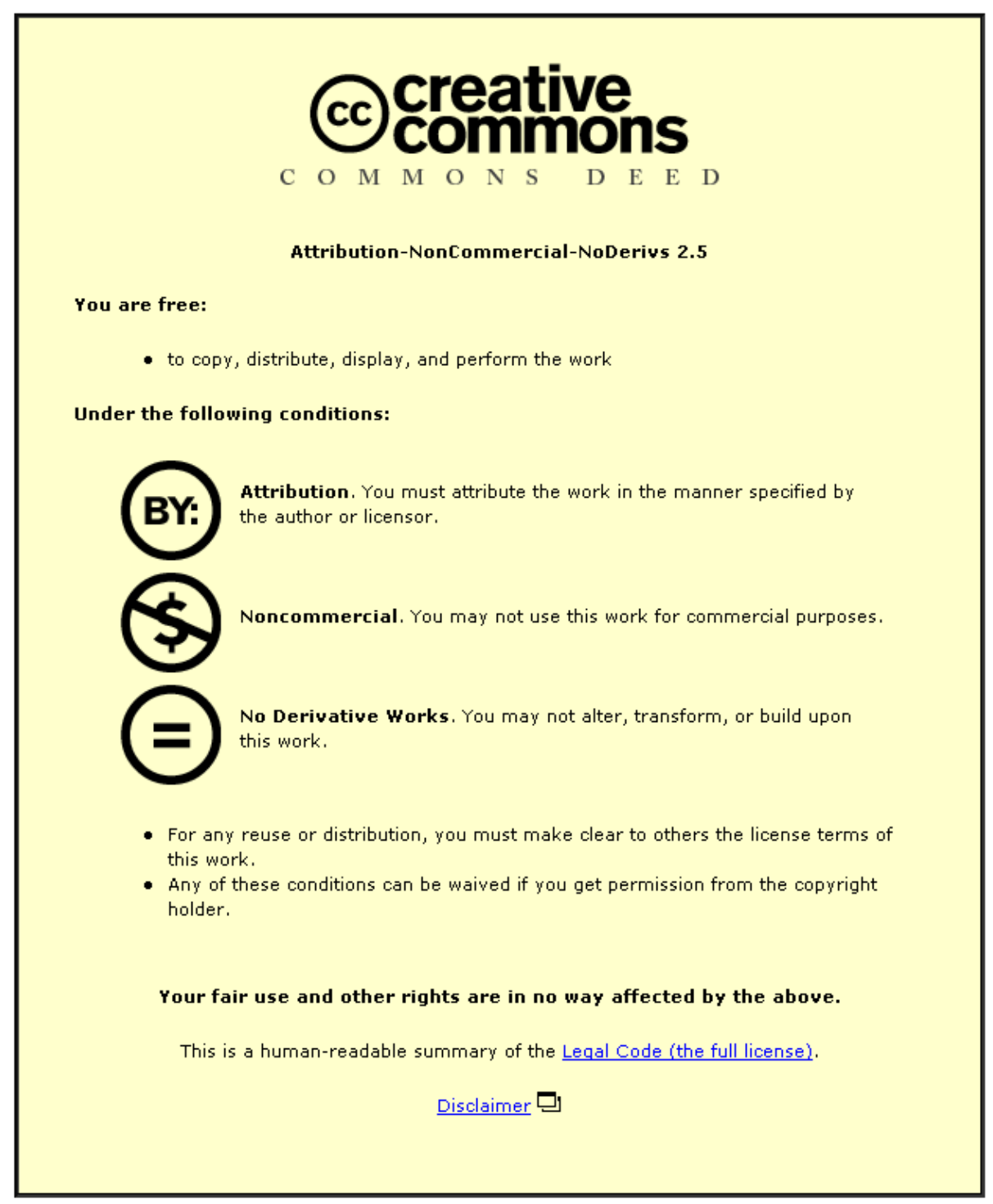

For the full text of this licence, please go to: http://creativecommons.org/licenses/by-nc-nd/2.5/ 


\title{
Investigation of the effect of relative humidity on polymers by depth sensing indentation
}

\author{
K. Altaf*, Ian A. Ashcroft, RichardHague \\ Wolfson School of Mechanical \& Manufacturing Engineering, Loughborough University, Leicestershire, LE11 3TU, UK
}

\begin{abstract}
Stereolithography (SL)resins absorb varying amounts of moisture dependent on the relative humidities, which can significantly affect the mechanical properties. In thiswork, the influence of relative humidity $(\mathrm{RH})$ on the mechanical behaviour of an SL resin is investigated using depth sensing indentation (DSI). The samples were conditioned by two methods. In the first method, samples werepre-conditioned at 33.5\%, 53.8\%, 75.3\%and 84.5\% RHusingsaturated salt solutions. These preconditioned samples were tested at $33.5 \%$ $\mathrm{RH}$, using a humidity control unit (HCU)to control RH in the DSI system. In the second method, samples were conditioned and tested at $33.5 \%, 53.8 \%, 75.3 \%, 84.5 \% \mathrm{RH}$ by regulating humidity in the DSI system using the HCU. Temperature was kept constant at $22.5^{\circ} \mathrm{C}$ for the conditioning and DSI testing.It was seen that hardness and modulus decreased with increasing $\mathrm{RH}$ and conditioning time but recovered significantlywhen tested after drying.This study demonstrates that $\mathrm{RH}$ needs to be taken into account when DSI testing of polymers.
\end{abstract}

Keywords: Nanoindentation;Stereolithography resin; Relative humidity; Moisture absorption.

\section{Introduction}

The additive approach to manufacturing enables designers to design complex geometries without the constraints and costs associated with conventional manufacturing techniques. This approach to manufacturing is termed rapid manufacturing (RM) or additive manufacturing (AM)[1].AM is becoming recognized as an alternative manufacturing technique but it still faces challenges, in particular the limitations of current AM materials, hence, material research is currently a major focus of work to make AM a reliable manufacturing method [2]. SL isone of the main processes of AM and is considered highly accurate and consistent[3]. However, owing to the sensitivity of SL materials to high levels of RHand long term UV

*Corresponding author. Tel.: +44 1509 227535; fax: +44 1509227648.

E-mail address: Kazim.Altaf@alumni.lboro.ac.uk (K. Altaf). 
degradation, the SL process has limited current use for producing end-use parts [4].One of the areas that requiresmajor development is the environmental stability of the SL materials postbuild.

In polymers, moisture absorption canlead to a wide range of effects, both reversible and irreversible, such as plasticization by weakening of the intermolecular interactions among the functional groups of the chains [5,6], de-bonding at filler-matrix interfaces [7-9], leaching of un-reacted functional groups [10],structural damage such as micro-cavities or crazes [11, 12], and chemical degradation of the polymer matrix due to hydrolysis and oxidation [11-13]. It can also involve the generation of free radicals or other reactive species, which may act as plasticizersor reactants[14, 15]. Long-term exposure can decreasethe molecular weight due to chain scission or the breaking of cross-links in the polymer network [16]. Absorbed moisture significantly affects the mechanical properties and glass transition temperature $\left(\mathrm{T}_{\mathrm{g}}\right)$ of polymeric materials $[6,7,9,17,18]$. The changes in mechanical property of polymeric components due to moisture absorption can be examined by performing mechanical testsafter moistureconditioning samples.

SL parts can exhibit spatial variations in their mechanical properties and this can be evaluated using DSI tests. However analysis of the results from the DSI testing of polymers is challengingbecause of their complex structure and time dependent deformation [19]. This time dependent viscoelastic (VE) or viscoplastic (VP) deformation leads to ambiguities in interpreting load-displacement curves and the miscalculation of modulus and hardness values [20]. When stress is applied to a polymer the molecular chains change position. The internal resistance to this is called the back stress, which decreases as the molecular structure reaches an equilibrium position. The difference between the applied stress and back stress is termed the overstress and can be considered to be the driving force for the creep. When the back stress is equal to the applied stress, the overstress is zero, creep stops and the polymer has an equilibrium deformation under the applied load. On release of the stress, the back stress carries recovery as there is now an overstress in the opposite direction to the applied stress.Depending upon the material type, this VE deformation can be partially or fully recoveredon removal of the load. If the applied load causes stresses to develop beyond a yield stress value, the deformation is called viscoplasticity.

Two approaches are usually employed to characterize the time dependent deformation of polymers by DSI. The first is to select test parameters to minimize VE/VP effects in order to obtain time independent results[21,22]. This is appropriate for polymers showing only weakly time dependent behaviour, e.g. at temperatures well below the glass transition 
temperature $\left(\mathrm{T}_{\mathrm{g}}\right)$. In order to minimise creep effects during initial unloading, careful selection of dwell time and loading and unloading rates is essential[22, 23]. However, the extracted properties must be related to the selected experimental parameters as they may vary with them.The second approach is to use DSI results to determine the parameters for a time dependent material model[24-26]. Whilst the latter approach is potentially the more useful one for characterising polymers, in this work we have adopted the approach of minimising the time dependent behaviour in order to simplify the analysis to enable the focus to remain on the effects of absorbed moisture and ambient humidity on the results of DSI.

There have been a number of studies on the nanoindentation of materials in a fully immersed environment using a liquid cell[27-31], but to date, no work has been reported where the effect of varying RH is investigated.In the present work, the time dependent mechanical behaviour of a SL resin is investigated under varying humidity conditions by using ahumidity control unit (HCU)to control the environment in aDSI machine.

\section{Material and experimental details}

The polymer investigated in this study is an epoxy based resin, Accura 60, manufactured by 3D Systems (Rock Hill, SC, USA). The samples were manufactured in a flat orientation using an SLA7000 SL machine,also from 3D Systems. The samples were 50x50 mm in dimension with $4 \mathrm{~mm}$ thickness. After manufacture, the samples were washed in chemical solvent; tripropylene glycol monomethyl ether (TPM) and cleaned with methanol. UV post-curing was employed for 30 minutes to stabilise and improve the mechanical properties of the samples. After being subjected to the post manufacture treatments, all the samples were stored in darkness in a dessicator for 20 days to ensure stability before testing. The NanoTest 600 , manufactured by Micro Materials (Wrexham, UK), was used for the DSI experiments. A Berkovich indenter with face angle of $65.3^{\circ}$, giving the same projected area to depth ratio as the Vickers indenter, was used to produce indents.

Environmental conditioning, carried at $22.5^{\circ} \mathrm{C}$, was divided into two parts. One set of dry samples was conditioned by using saturated chemical salt solutions inside glass flasks and the other set was conditioned inside the DSI chamber using theHCU.In order to condition samples inside glass flasks, saturated salt solutions were used to provide a controlled humidity. The salts used were; magnesium chloride, magnesium nitrate, sodium chloride and potassium chloride to provide relative humidities of $33.5 \%, 53.8 \%, 75.3 \%$ and $84.5 \%$ respectively, with $\pm 1 \%$ variation. The conditioning of samples inside the DSI chamber was carried outby regulating RHto $33.5 \%, 53.8 \%, 75.3 \%$ and $84.5 \%$ RHwith $\pm 1 \%$ variationusing 
the HCU. The HCU consists of an ultrasonic humidifier, a dehydration section and acontrol box with humidity sensors. The ultrasonic humidifier consists of a humidifier and circulating fan. This is controlled by activating a relay that switches on the humidifier and circulating fan when $\mathrm{RH}$ is below the required level. Once this level is reached, fan and humidifier are switched off. The dehydration section consists of a polycarbonate box containing several layers of desiccant and a circulating fan. When $\mathrm{RH}$ in the chamber is greater than the desired value, the humidity controlleractivates a fan circulating moist air over the desiccant.

Prior to use of the HCU in testing the Accura 60 samples, it was first necessary to check the correct functioning of the DSI system in the range of controlled humidities to be used in the test programme. In order to achieve this DSI tests were carried out on fused silica samples at $33.5 \% \mathrm{RH}$ and $84.5 \% \mathrm{RH}$ at $1 \mathrm{mN}, 20 \mathrm{mN}$ and $50 \mathrm{mN}$ loads. Results showed that the mechanical properties of the silica were not significantly affected by the humidity (maximum change less than $2.5 \%$ ), confirming that the integrity of data from the DSI system is not affected by the use of HCU.

Thermal stability is also important when performing nanoindentation tests on polymers as variations can affect the extracted properties. Although the temperature inside the room and cabinet were controlled and experiments were performed at constant temperature there was still the possibility of thermal drift as the experiments were performed for long periods of dwell time.The DSI machine was tested for thermal drift at $1 \mathrm{mN}, 20 \mathrm{mN}$ and $50 \mathrm{mN}$ loads at 300 s hold time by performing tests on fused silica samples at $33.5 \%$ and $84.5 \% \mathrm{RH}$. The average value of drift for all experiments remained below $0.8 \mathrm{~nm} / \mathrm{min}$ and there was no significant difference between the $33.5 \%$ and $84.5 \%$ RH results.

In order to minimise the effect of rate dependent deformation on indentation hardness and modulus values and selecting appropriate testing parameters, three parameters; loading rate, unloading rate and hold period were investigated. Experiments were performed on dry samples with $33.5 \% \mathrm{RH}$ inside the chamber and $20 \mathrm{mN}$ maximum load.Each parameterwas varied in turn while keeping the others constant. The maximum load was selected to obtainan appropriate indentation depth where the effects of indenter tip and surface roughness are negligible but the effects of changes in surface moisture are readily observed.Five indentations, at $150 \mu \mathrm{m}$ spacing, were performed to obtain the average values for hardness and modulus using the Oliver and Pharr (OP) method [32]. It should be noted that whilst the values of $\mathrm{E}$ and $\mathrm{H}$ determined using the $\mathrm{OP}$ method are not directly relevant to the material properties of a viscoelastic material, they can be used to make relevant comparison if the limitations are acknowledged. 
In order to investigate effects of moisture on samples stored at $33.5 \%, 53.8 \%, 75.3 \%$ and $84.5 \% \mathrm{RH}$ in flasks, samples were tested at 33.5\% RH inside the chamber every 24 hours for five days. To maintain uniformity in the experiments, each sample was tested within half an hour of removal from the flask. Testing was carried out at $0.5 \mathrm{mN} / \mathrm{sec}$ loading and unloading rates with $300 \mathrm{~s}$ dwell time at $20 \mathrm{mN}$ maximum load. Series of five indentations at $150 \mu \mathrm{m}$ apart were made and test data was analysed using the OP method.Dry samples were also conditionedfor five days in the DSIchamber at 33.5\%, 53.8\%, 75.3\%, and $84.5 \% \mathrm{RH}$ and tested every 24 hours. For comparison with the samples conditioned in flasks, the testing parameters were kept the same. In order to investigate any recovery in mechanical properties on drying, the samples conditioned at $84.5 \% \mathrm{RH}$ for five days in the DSI chamber were then conditionedat 33.5\% RHfor ten days and retested periodically.Again, thetesting parameters were kept the same as those described above.Tests were also carriedat different loads ranging from 1 to $20 \mathrm{mN}$ to investigate the effects of indentation load on depth under moisture. Dwell period and loading and unloading rates were kept the same as described earlier.

\section{Resultsand discussion}

Dry samples tested at $33.5 \% \mathrm{RH}$ inside chamber

Testing with different loading rates andfixed unloading rate of $0.5 \mathrm{mN} / \mathrm{sec}$ and no dwell period at $20 \mathrm{mN}$ maximum load showed that the maximum indentation depth increases with decrease in loading rate and that fast loading produces a more pronounced 'nose' or 'bowing' effect in the initial segment of the unloading curve that results in an initial negative gradient to the unloading curves, which means that the calculation of elastic modulus, E, andplastic depth, $\mathrm{h}_{\mathrm{p}}$, using the OP method is meaningless. Similarly, the effect of change in unloading rate, when the loading rate was kept constant at $0.5 \mathrm{mN} / \mathrm{sec}$, showed that the samples demonstrate significant creep behaviour when unloaded at lower rates. Finally, testing at constant loading and unloading rates of $0.5 \mathrm{mN} / \mathrm{sec}$ with $0 \mathrm{~s}, 120 \mathrm{~s}, 180 \mathrm{~s}, 300 \mathrm{~s}$ and $600 \mathrm{~s}$ dwell times at $20 \mathrm{mN}$ maximum load showed that the bowing effectdecreasedwith an increase in dwell time.The gradient of the initial segment of the unloading curve remainedapproximately same with dwell periods greater than $300 \mathrm{sec}$.Hence, on the basis of these results, $0.5 \mathrm{mN} / \mathrm{sec}$ loading and unloading rates with a $300 \mathrm{sec}$ dwell time at $20 \mathrm{mN}$ maximum load were the selected parameters for this research work. Therefore, by applying a suitable dwell period with moderate loading and unloading rates, time dependent effects during unloading can be minimized and $\mathrm{E}$ can be related to the elastic component of deformation and $\mathrm{H}$ to the mean 
pressure under the indenter at pseudo-equilibrium deformation, when creep has nearlystopped.Whilst these two values don't fully characterise complex time dependent mechanical behaviour of the polymers, they do allow meaningful comparisons to be made of the effect of moisture on the mechanical performance of the material, which is the main subject of intent in this paper.

Samples preconditioned in flask and tested at 33.5\%RH inside the DSI chamber

Figure 1 shows a comparison of load-depth plots for samples preconditioned for 24 hours at different relative humidities and tested at $33.5 \% \mathrm{RH}$ in the DSI chamber.It can be seen thatmaximum indentation depth increaseswith increasing RH. This can be attributed to absorption of more moisture by polymer at higher $\mathrm{RH}$. The absorbed moisture weakens the intermolecular forces in the polymer resulting in a decrease in the glass transition temperature $\left(\mathrm{T}_{\mathrm{g}}\right)$ and a decrease in resistance to indentation[27, 28, 33]. Figures 2 and 3 show plots of $\mathrm{H}$ and $\mathrm{E}$ as functions of conditioning time for various environments. It is interesting to see that values of both $\mathrm{E}$ and $\mathrm{H}$ are relatively insensitive to conditioning time at $33.5 \% \mathrm{RH}$, which indicates that the saturated moisture content at $33.5 \% \mathrm{RH}$ at $22.5^{\circ} \mathrm{C}$ has only a modest effect on the mechanical properties. However, at $75.3 \%$ and $84.5 \% \mathrm{RH}$, the values of $\mathrm{E}$ and $\mathrm{H}$ decreased significantly with conditioning time. This trend highlights an increase in surface moisture concentration with an increase in conditioning time. Rates of change in $\mathrm{E}$ and $\mathrm{H}$ decreased with time as surface layers reach an equilibrium moisture content.

Samples conditioned and tested at various RH inside the DSI chamber

Figure 4 shows the load-depth plots for samples conditioned for 24 hours at various relative humiditiesby regulating $\mathrm{RH}$ using the $\mathrm{HCU}$ in the DSI chamber and testing at the same controlled RH. It can be seen thatmaximum indentation depth increases with an increase in $\% \mathrm{RH}$, with samples at $84.5 \% \mathrm{RH}$ showing the maximum penetration. The rising $\mathrm{RH}$ in the environment increases the absorbed moisture concentration in the sample surface and thus influences the resistance to indentation, as discussed in section 3.2.Figures 5 and 6 show plots of calculated $\mathrm{H}$ and $\mathrm{E}$ as functions of conditioning time for various environments. Values of both $\mathrm{E}$ and $\mathrm{H}$ are, again, not significantly affected by conditioning time at $33.5 \% \mathrm{RH}$ while at $75.3 \%$ and $84.5 \% \mathrm{RH}$, the values of $\mathrm{E}$ and $\mathrm{H}$ decreased significantly with the conditioning time. 
Comparison between preconditioned and HCU conditioned samples

Comparison of Figures1and4 shows that penetration depth for a given timeand $\mathrm{RH}$ is greater for the samples conditioned and tested in the same environment than for the preconditioned samples tested at the ambient humidity of 33.5\%RH.The exception being the samples conditioned at $33.5 \% \mathrm{RH}$ which show similar results for both conditioning methods, as would be expected. This observation can be seen more clearly in Figures 7 and 8 which shows that the values of $\mathrm{H}$ and $\mathrm{E}$ for a given conditioning environment are greater for the preconditioned samples. This is because tests were at a lower RH than the conditioning environment, resulting in desorption of some of the moisture from the sample surface during the period of the test. Even though the testing was conducted as quickly as possible after removal from the conditioning environment, the effect is quite significant, especially at high RH. These results also show that SL resin is highly hygroscopic, especially when stored and/or tested at high values of humidity, and that the absorbed moisture significantly affects the mechanical properties. This indicates that the mechanical performance of manufactured parts using SL materials will vary as a function of the RH, which should be accounted for when designing with these materials. The effects of moisture on polymers can be either reversible or irreversible and this is investigated in the next section.

\section{Retesting of conditioned samples after drying}

Figure9 compares load-depth plots of samples conditioned at $84.5 \% \mathrm{RH}$ for 5 days and tested at $84.5 \% \mathrm{RH}$ with plots of same sampleswhenretained for 10 days at $33.5 \% \mathrm{RH}$ inside the chamber and tested periodically. It can be seen that the maximum indentation depth decreases with drying time, indicating that some of the effects of moisture on the SL properties are reversible. Figure 10 shows a comparison of $\mathrm{E}$ and $\mathrm{H}$ values for these samples before and after drying. It is apparent from the plots that the drying process has partially reversed the mechanical properties of the Accura 60 samples.Initially, the process is fast,reducingas equilibrium of moisture concentration between the sample surface and the environment is reached. After 10 days storage in ambient, the average regain in hardness was $68.43 \%$ and in modulus $76.12 \%$. Improvementin the mechanical properties on drying can be attributed to reversible changes in AM polymers on removal of the moisture, which has been noted previously for epoxy based polymers [34, 35].

Hardness as a function of indentation depth 
Figure 11 shows hardness as a function of depth for samples conditioned for various times at $84.5 \% \mathrm{RH}$ when different maximum indentation loads were used. Results of dry samples tested at $33.5 \% \mathrm{RH}$ are also provided for the comparison purposes. With the dry samples it can be seen that there is little change in hardness with depth, indicating no significant surface effects to the mechanical properties. The samples conditioned for 5 days also show little change in hardness with depth, although in this case at a significantly lower hardness. This is because in this case the polymer has reached moisture saturation to at least the depth of the indentation. The constant value is hence the value of hardness for the saturated material for these conditions. The samples conditioned for 4 and 12 hours have intermediate hardness between the dry and saturated samples and also show depth dependence, with hardness being lower at the surface where the moisture concentration is highest. This is a similar result to that observed previously by Ashcroft and Spinks [27].

\section{Conclusions}

Results showed that mechanical properties of SL resin were dependent on the RH of the environment and that a DSI fitted with a HCU was capable of investigating this relationship. Comparison of the results with thepre-conditionedsamplestested at ambient conditions showed that drying the samples whilst testing can affect the results. Hence, there is an argument to always using a HCU to control RH within the DSI chamber during testing of moisture dependent materials. Also, HCU can virtually cover all ranges of moisture contents which can be useful for DSI testing of many biological samples. Additionally, degree of absorbed moisture in a part and the spatial variation in moisture may also be investigated.

Results show that current epoxy resins proposed for SL based additive manufacturing are highly hygroscopic and their mechanical performance varies significantly with the ambient humidity. Therefore, the effect of moisture in environment clearly needs to be taken when designing parts. Experiments on samples after drying showed substantial, though not complete, recovery in the values of $\mathrm{E}$ and $\mathrm{H}$.

\section{References}

[1] Rosen DW (2007) Comput Aided Des Applic 4 (5):585

[2] Wu M, Zhao W, Tang Y et al (2001) Rapid Prototyping Journal 7(5):268 
[3] Hague R, Campbell I, Dickens P (2003) Proc Inst Mech Eng Part C 217(1):25

[4] Liu XY, Jiang J (2003) Rapid Prototyping Journal 9(2):88

[5] Ivanova K, Pethrick R, Affrossman S (2000) Polymer 41(18):6787

[6] Park Y, Ko J, Ahn TK et al (1997) J Polym Sci, Part-B: Polym Phys 35(5):807

[7] Bowditch M (1996) Int J Adhes Adhes 16(2):73

[8] Kasturiarachchi K, Pritchard G (1985) J Mater Sci 20(6):2038

[9] Kumazawa T, Oishi M, Todoki M (1994) IEEE Trans Dielectr Electr Insul 1(1):133

[10] Antoon M, Koenig J (2003) J Polym Sci, Part B: Polym Phys 19(2):197

[11] Apicella A, Nicolais L, Astarita G et al (1979) Polymer 20(9):1143

[12] Diamant Y, Marom G, Broutman LJ (2003) J Appl Polym Sci 26(9):3015

[13] Hamid SH (2000) Handbook of polymer degradation. 2nd ed, Marcel Dekker, New York

[14] Ritter JE, Fox JR, Hutko DI et al (1998) J Mater Sci 33:4581

[15] Verdu J, Salmon L, Thominette F et al (1996) Composites Science and Technology 57(8): 1119

[16] McKague Jr EL, Reynolds JD, Halkias JE (2003) J Appl Polym Sci 22(6):1643

[17] Butkus LM, Mathern PD, Johnson WS (1998) J Adhes 66(1):251

[18] St. Lawrence S, Willett JL, Carriere CJ (2001) Polymer 42(13):5643

[19] Fischer-Cripps AC (2004) Mater Sci Eng, A 385(1-2):74

[20] Feng G, Ngan AHW (2002) J Mater Res 17(3):660

[21] Cheng CM, Cheng YT (1997) Appl Phys Lett 71:2623

[22] Chudoba T, Richter F (2001) Surf Coat Technol 148(2-3):191

[23] Briscoe BJ, Fiori L, Pelillo E (1998) J Phys D: Appl Phys 31:2395

[24] Oyen ML, Cook RF (2009) Journal of the Mechanical Behavior of Biomedical Materials 2(4):396

[25] Oyen ML, Cook RF (2003) J Mater Res 18(1):139

[26] Mencík J, He LH, Swain MV (2009) Journal of the Mechanical Behavior of Biomedical Materials 2(4):318 
[27] Ashcroft IA, Spinks GM (1996) J Mater Res 11(2):529

[28] Gerard AB, Dariusz MB, Ben DB (2008) J Appl Polym Sci 107(1):577

[29] Yang B, Min Huang W, Li C et al (2005) European Polymer Journal 41(5):1123

[30] Akhtar R, Morse S, Mummery PM (2005) Mat Res Soci Symp Proc 844:15

[31] Hengsberger S, Kulik A, Zysset PH (2002) Bone 30(1):178

[32] Oliver WC, Pharr GM (1992) J Mater Res 7(6):1564

[33] Gaofei Z, Yilan K, Jing S et al (2004) Sci China, Ser E Eng Mater Sci 47(5):595

[34] Mubashar A, Ashcroft IA, Critchlow GW, Crocombe AD (2010) J Adhes

[35] Mubashar A, Ashcroft IA, Critchlow GW, Crocombe AD (2009) Int J Adhes Adhes 29:751 


\section{Figures Caption:}

Figure 1: $\quad$ Load-depth plots of samples preconditioned under various environments for 24 hours and tested at $33.5 \% \mathrm{RH}$.

Figure 2: Indentation hardness as function of time after pre-conditioning at various relative humiditiesand testing at $33.5 \% \mathrm{RH}$.

Figure 3: Indentation modulus as function of time after pre-conditioning at various relative humiditiesand testing at $33.5 \% \mathrm{RH}$.

Figure 4: $\quad$ Load-depth plots for samples conditioned by HCU for 24 hours under various $\% \mathrm{RH}$ and tested under the same conditioning environment.

Figure 5: Indentation hardness as function of time after conditioning and testing under various relative humidities regulated by $\mathrm{HCU}$.

Figure 6: Indentation modulus as function of time after conditioning and testing under various relative humidities regulated by $\mathrm{HCU}$.

Figure 7: Comparison of indentation hardness of samples conditioned for five days in flask and tested at 33.5\%RH with samples conditioned for five days and tested under various $\% \mathrm{RH}$ regulated by $\mathrm{HCU}$.

Figure 8: $\quad$ Comparison of indentation modulus of samples conditioned for five days in flask and tested at $33.5 \% \mathrm{RH}$ with samples conditioned for five days and tested under various $\% \mathrm{RH}$ regulated by $\mathrm{HCU}$.

Figure 9: $\quad$ Comparison of load-depth plot for samples initially dry with those conditioned for five days at $84.5 \% \mathrm{RH}$ and tested at $84.5 \% \mathrm{RH}$ and with samples conditioned for 5 days at $84.5 \% \mathrm{RH}$ and followed by conditioning at $33.5 \% \mathrm{RH}$.

Figure 10: Recovery in indentation modulus and hardness on drying samples that were conditioned for 5 days under $84.5 \% \mathrm{RH}$ and retested periodically at $33.5 \% \mathrm{RH}$.

Figure 11: Indentation hardness as a function of indentation depth for samples conditioned and tested aftervarious times at $84.5 \% \mathrm{RH}$. 


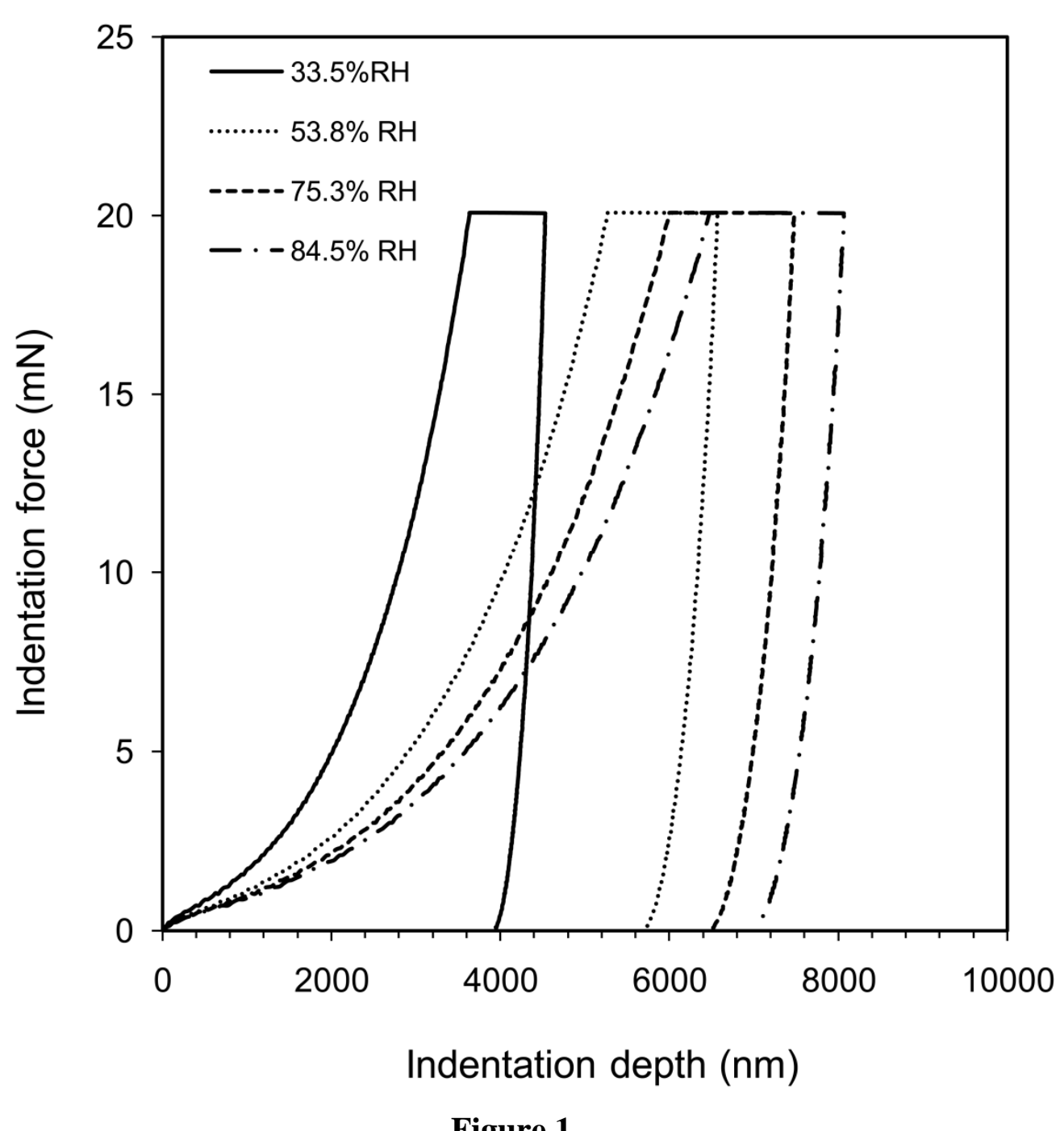

Figure 1 


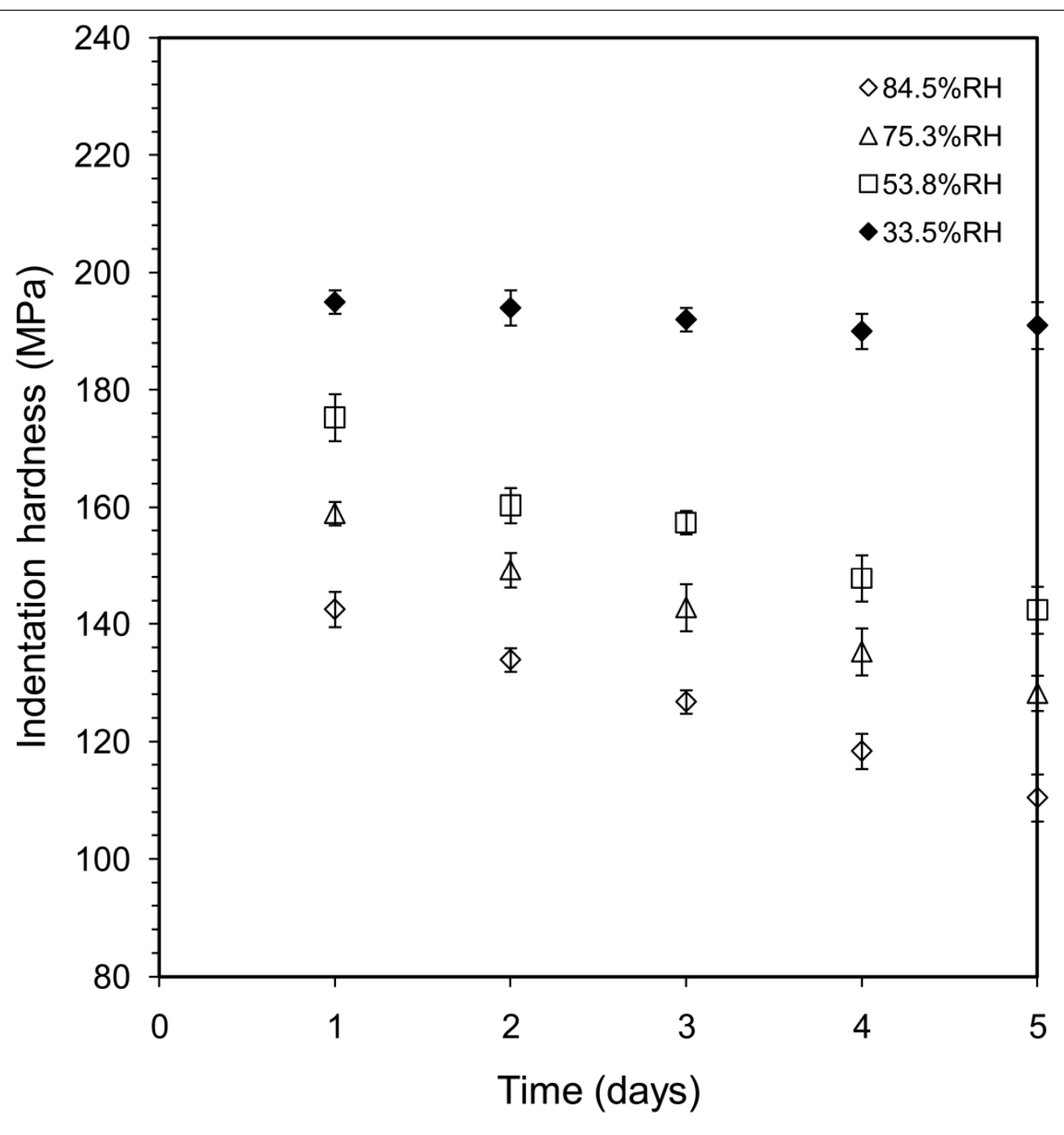

Figure 2 


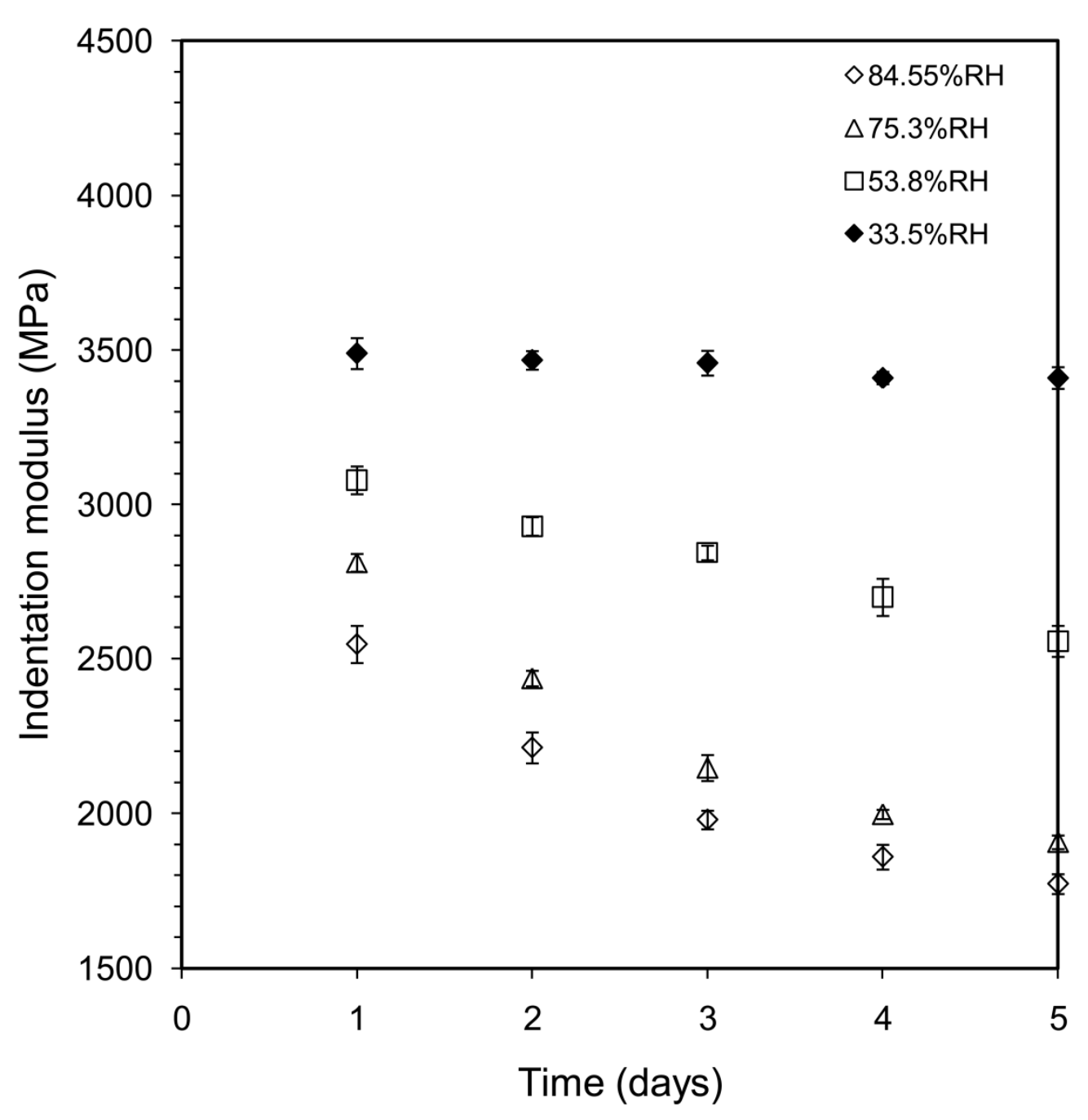

Figure 3 


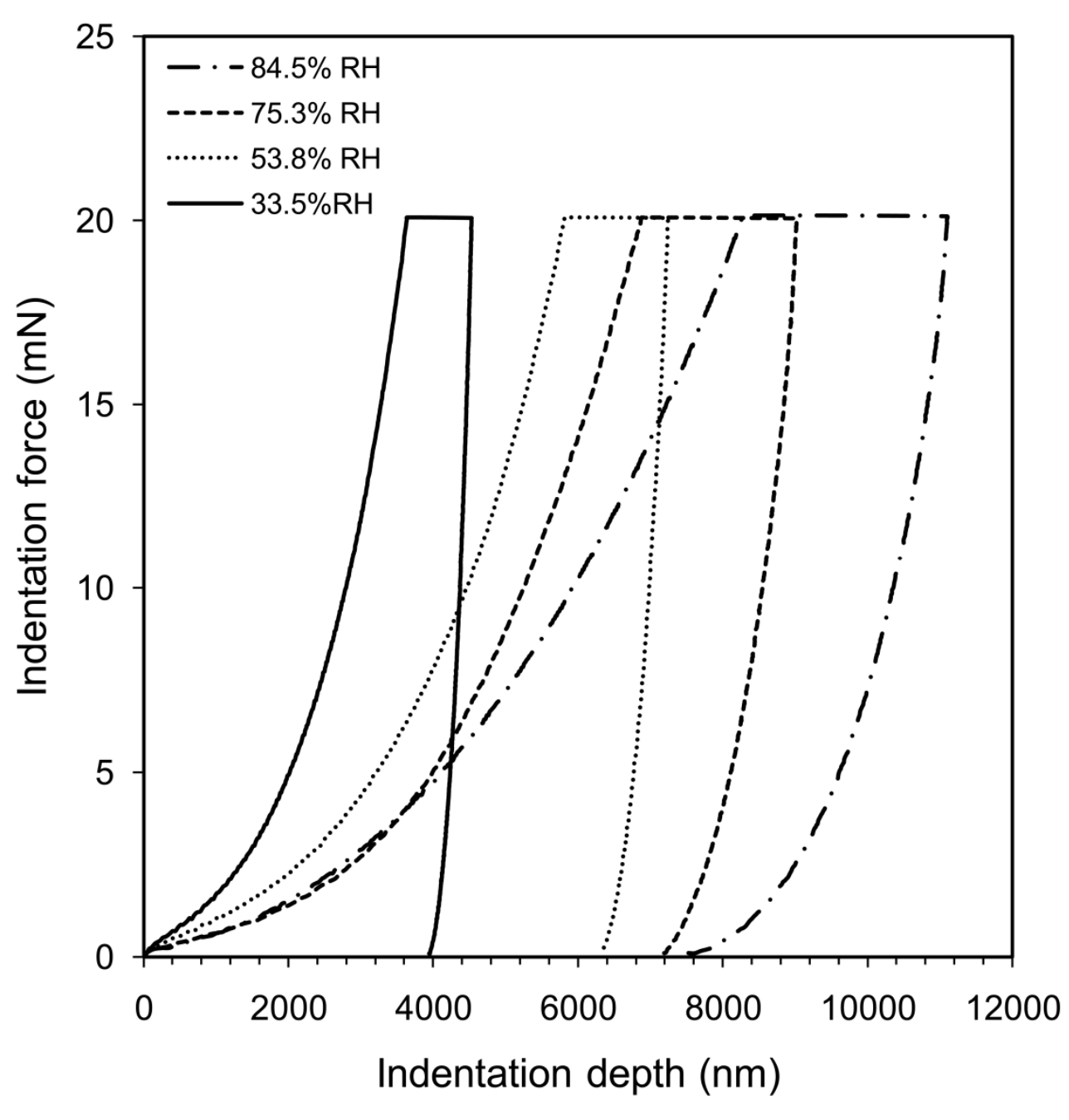

Figure 4 


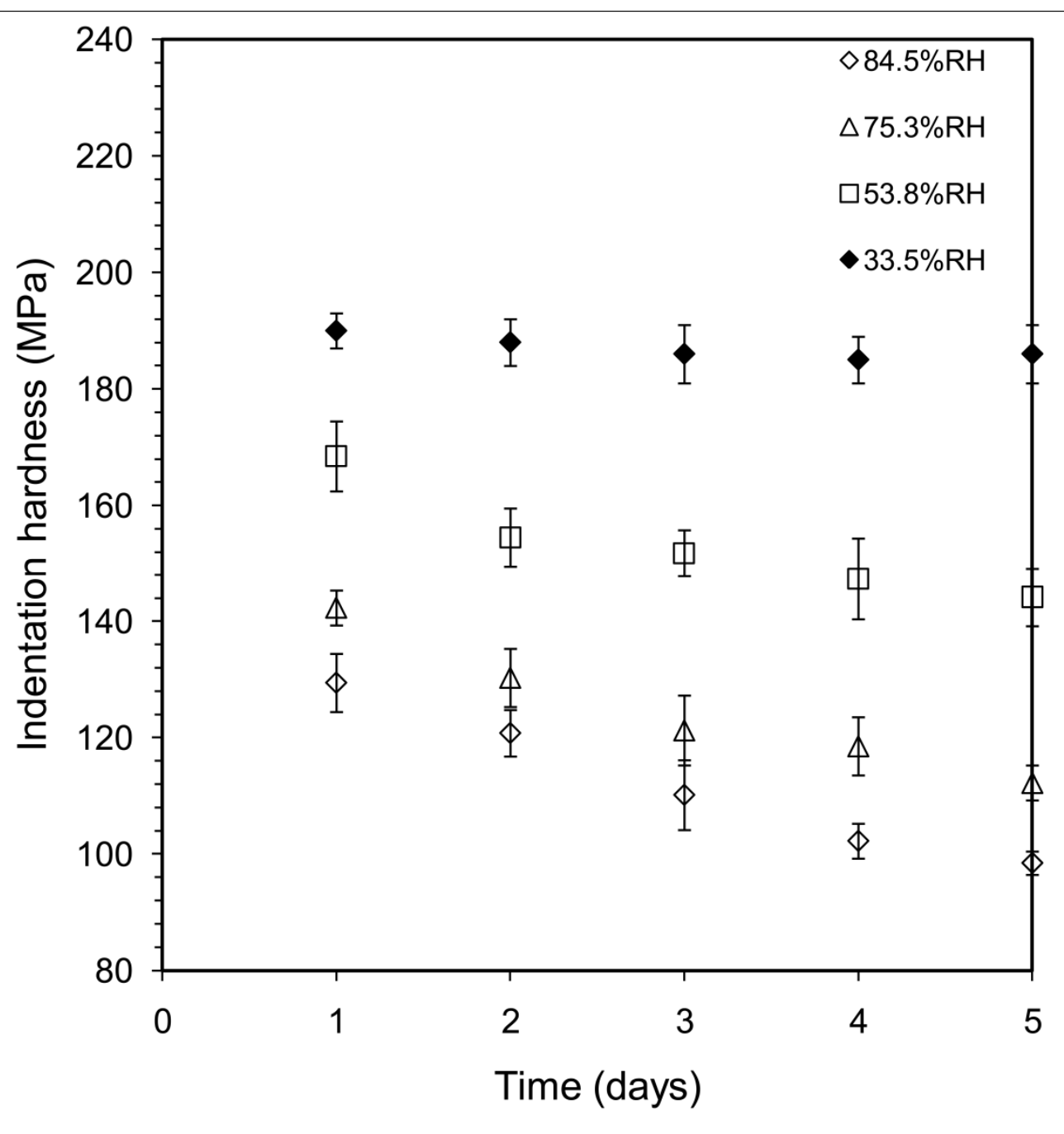

Figure 5 


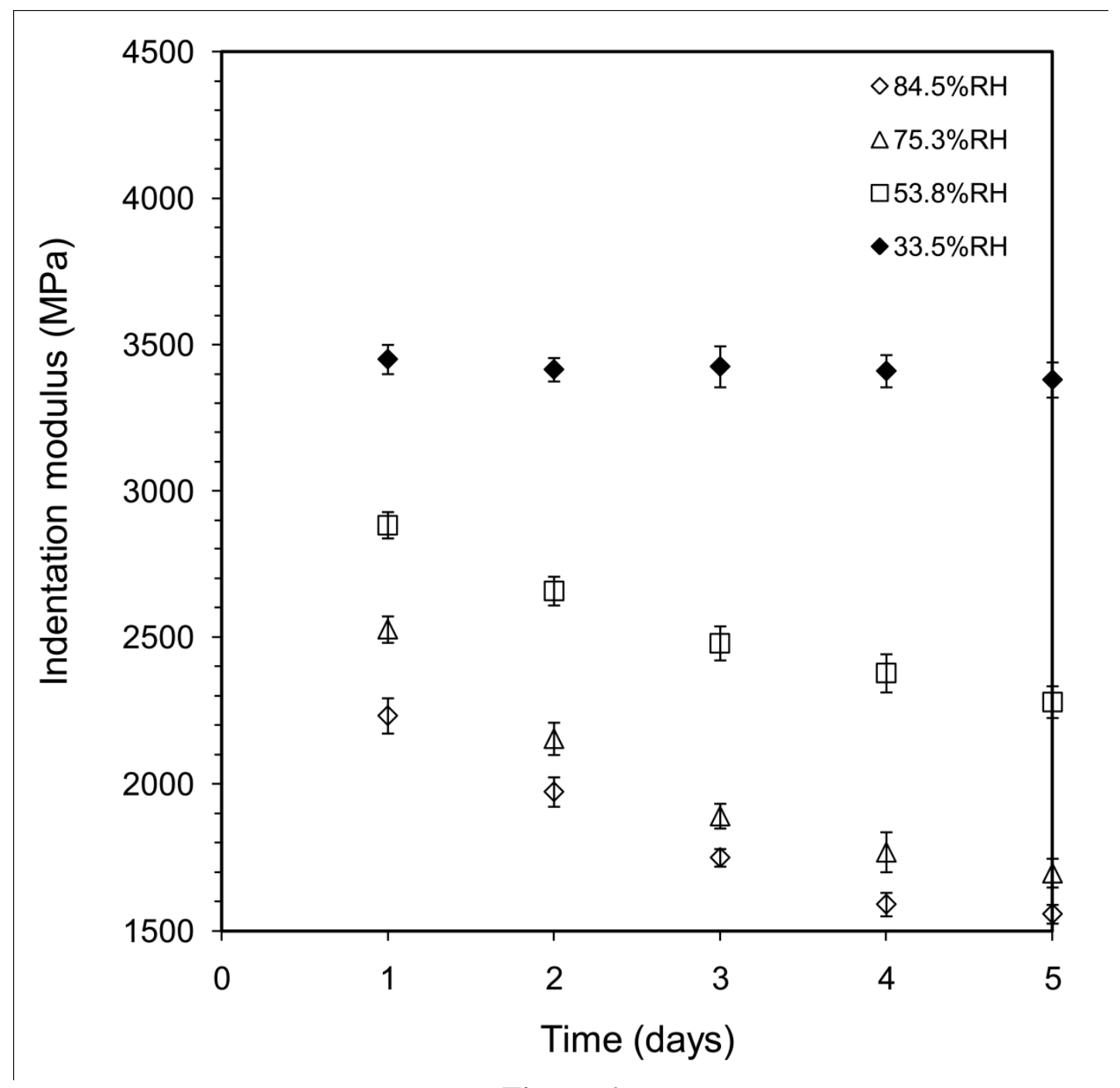

Figure 6 


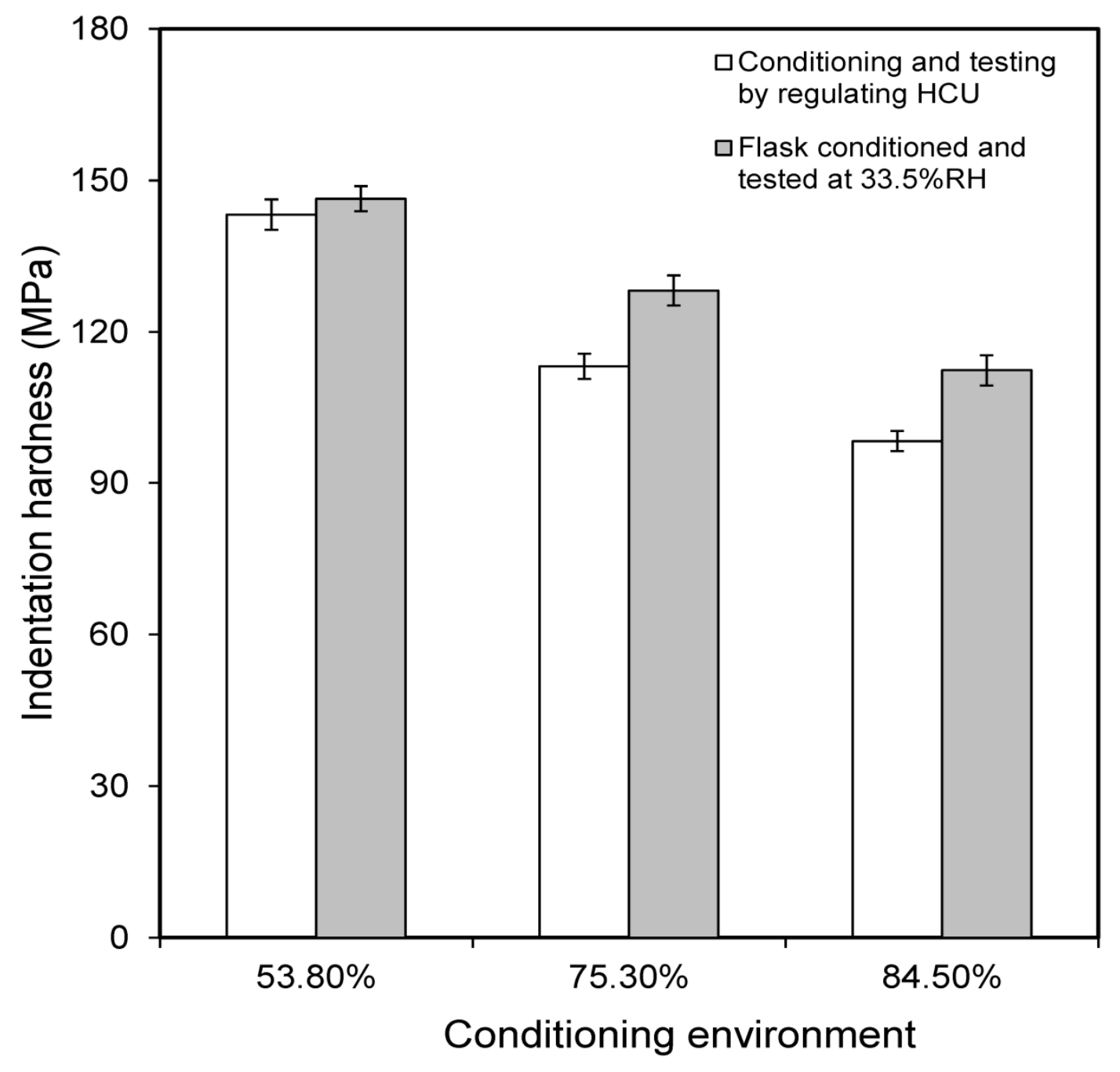

Figure 7 


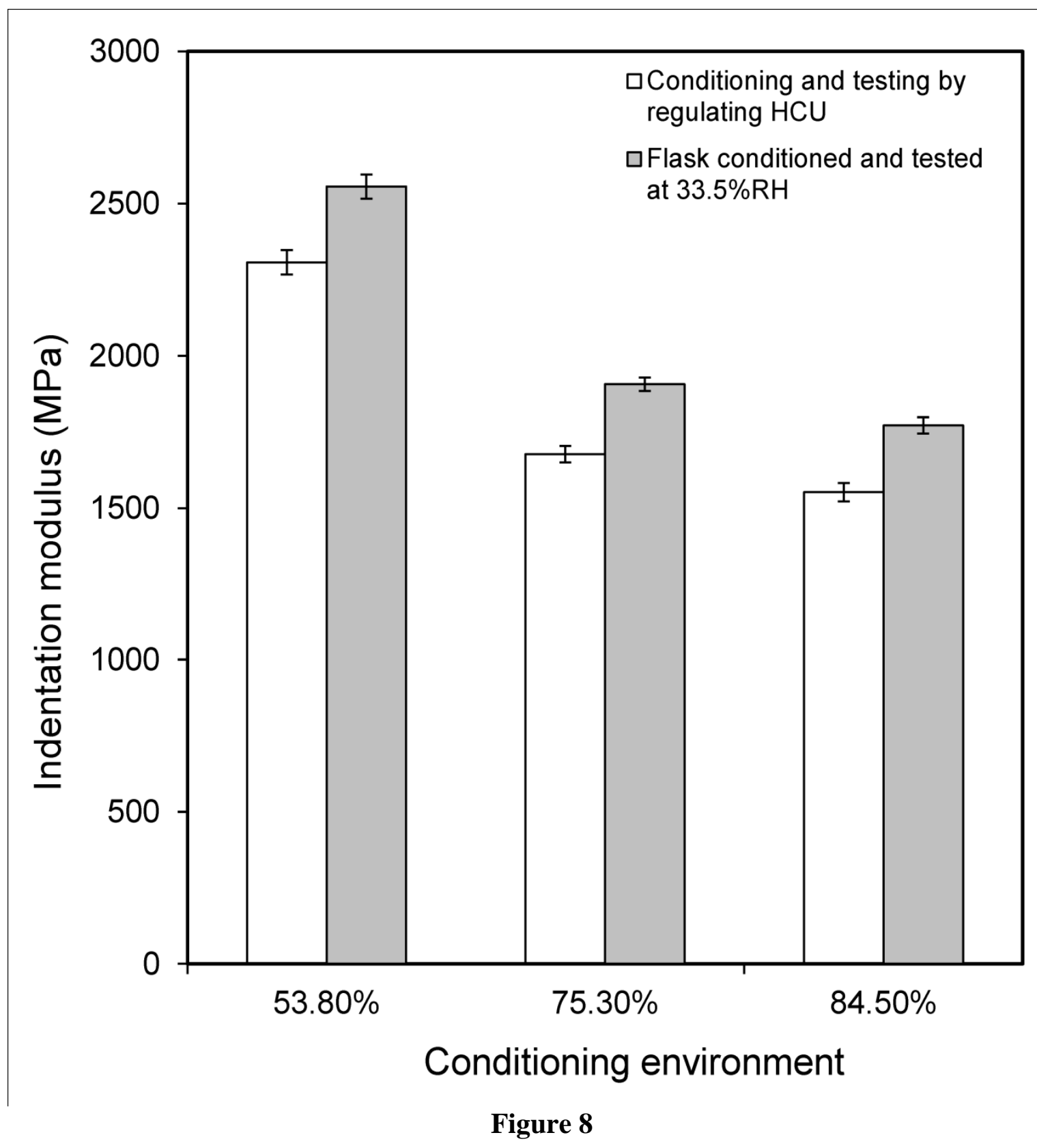




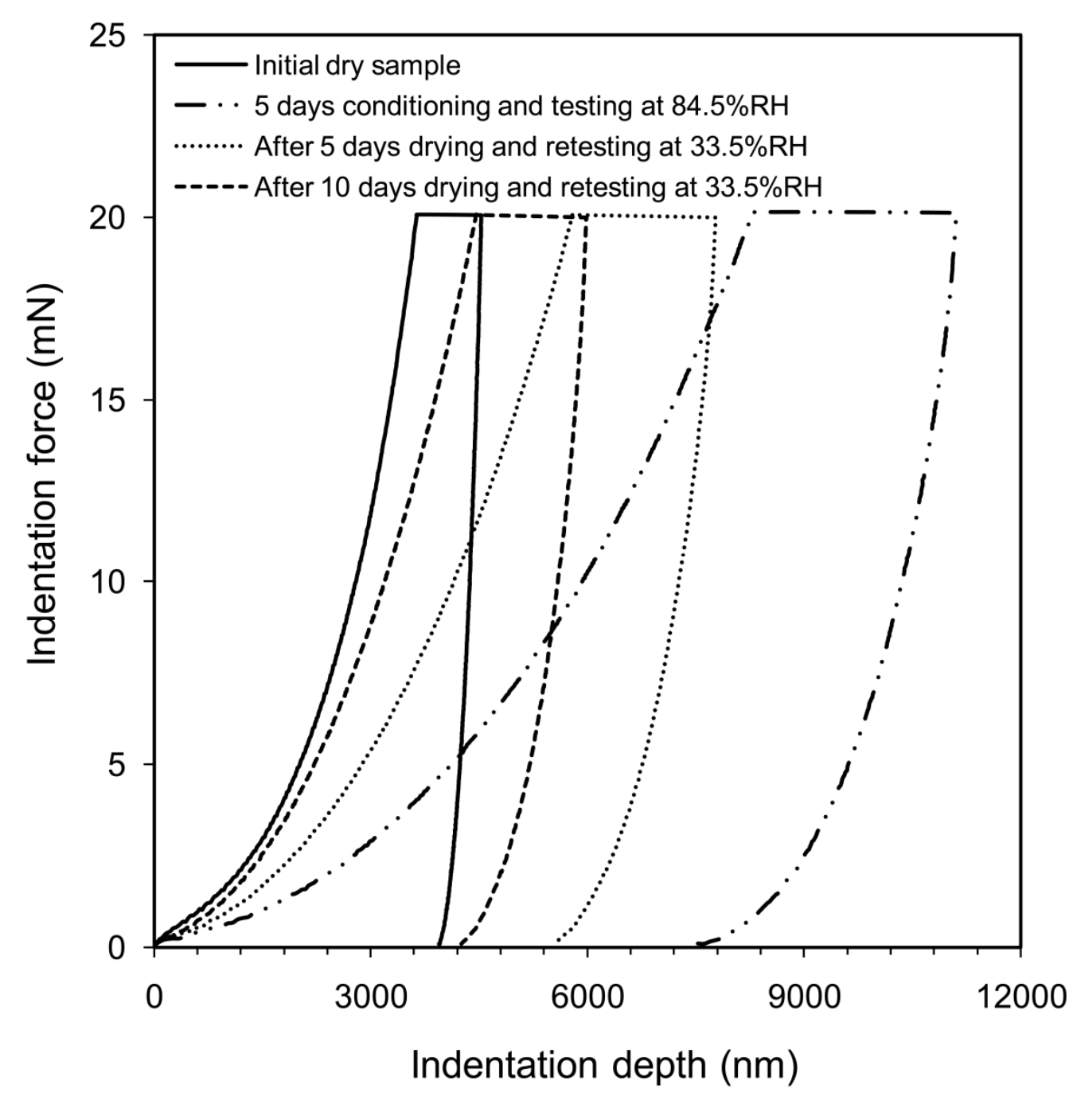

Figure 9 


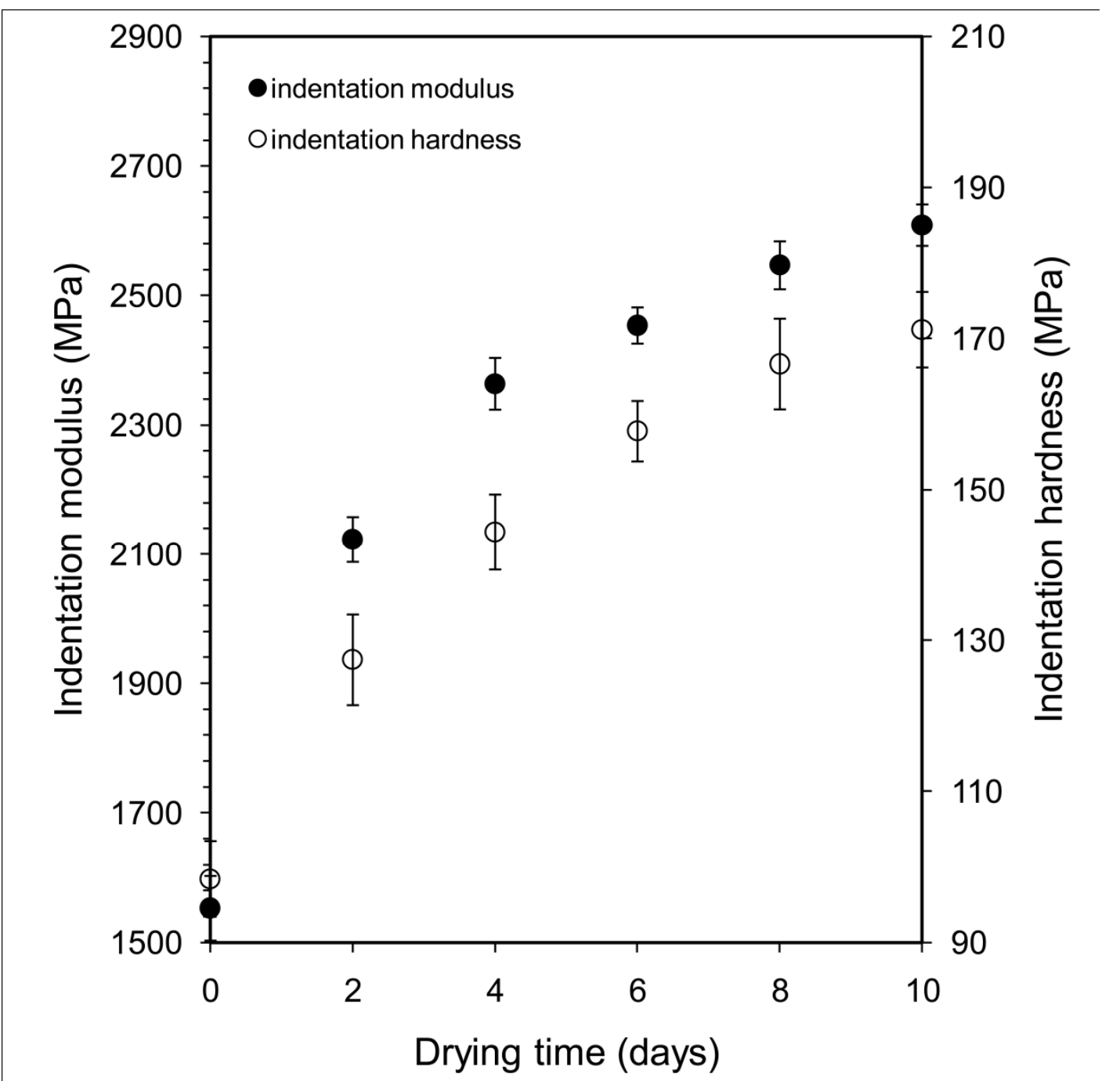

Figure 10 


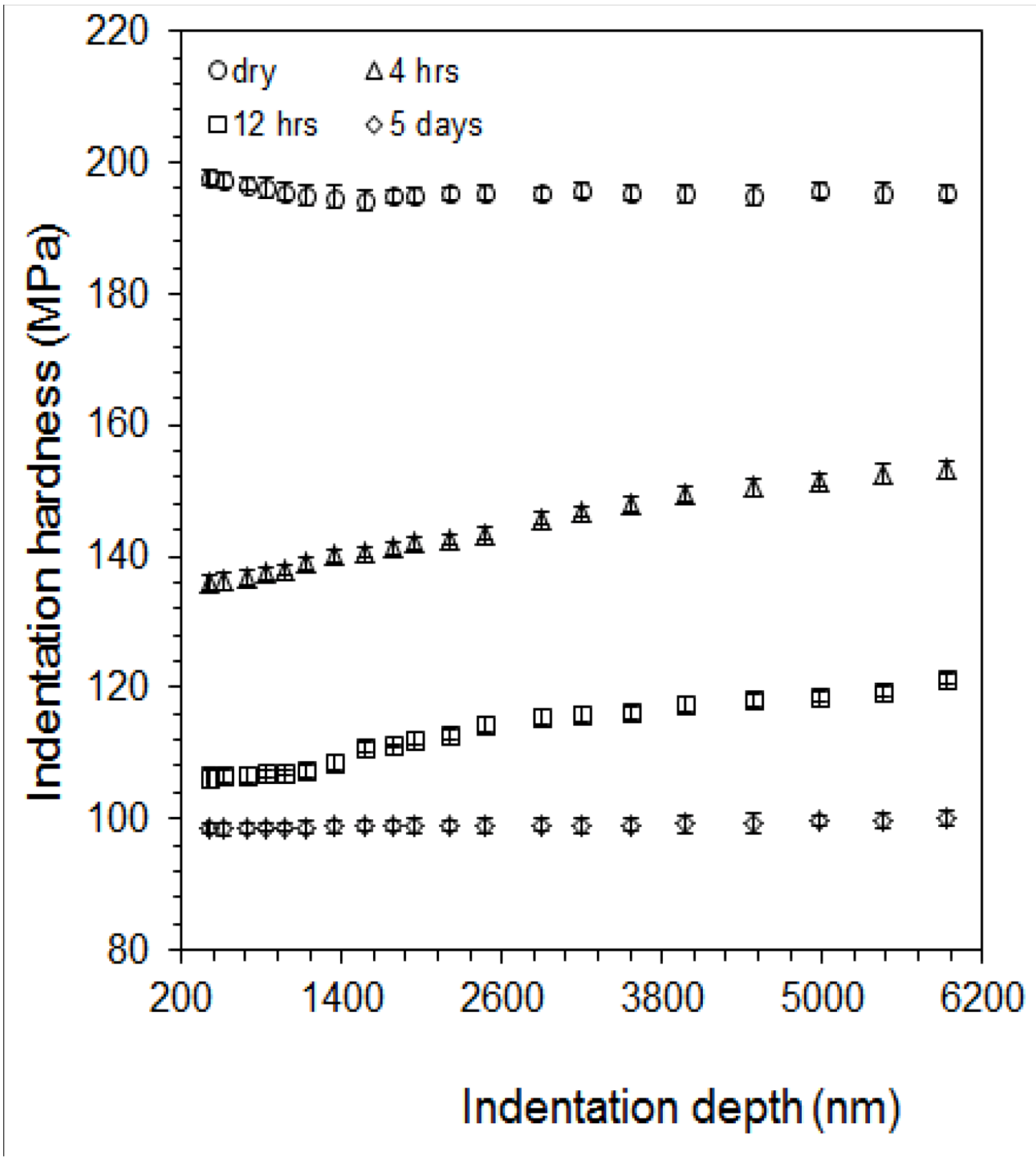

Figure 11 